Received: 18 May 2017

Accepted: 4 October 2017

Published online: 20 October 2017
NTIFIC REP

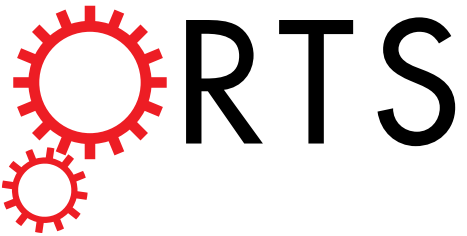

OPEN

Cyclobutane-1,3-Diacid (CBDA): A Semi-Rigid Building Block Prepared by [2+2] Photocyclization for Polymeric Materials

Zhihan Wang ${ }^{1}$, Benjamin Miller ${ }^{1}$, Micah Mabin ${ }^{1}$, Rahul Shahni ${ }^{1}$, Zijun D. Wang ${ }^{1}$, Angel Ugrinov ${ }^{2}$ \& Qianli R. Chu ${ }^{1}$

A previously overlooked building block, cyclobutane-1,3-diacid (CBDA), is introduced to materials synthesis due to its great potentials. As an example of CBDA, $\alpha$-truxillic acid or 2,4-diphenylcyclobutane-1,3-dicarboxylic acid, was readily synthesized from commercially available trans-cinnamic acid. This CBDA showed outstanding stability both in sunlight and upon heating. While its two carboxylic acid groups can be readily utilized in connecting with other molecules to form new materials, the cyclobutane ring was able to tolerate acid and base treatments showing good chemical stability. A series of cyclobutane-containing polymers (CBPs), namely poly- $\alpha$-truxillates, were obtained by condensation between $\alpha$-truxillic acid and diols including ethylene glycol, 1,3-propanediol, 1,4-butanediol, 1,5-petanediol, and 1,6-hexanediol. The structures of these poly- $\alpha$-truxillates were analyzed by NMR, FT-IR, and HRMS. Powder X-ray diffraction results of the poly- $\alpha$-truxillates indicated that they are semi-crystalline materials. Preliminary thermal, chemical, and photochemical tests showed that the poly- $\alpha$-truxillates exhibited comparable stabilities to PET.

Since the dawn of civilization, the development of new materials has been the driving force behind technological advancement, and in the modern era, few materials have had a broader impact than synthetic polymers. Herein, we suggest that cyclobutane-1,3-diacid (CBDA) should be included as a semi-rigid building block in the research efforts to synthesize polymers ${ }^{1,2}$ and other materials such as metal-organic frameworks (MOFs) ${ }^{3,4}$. As a case study of CBDA, we present the monomer, trans-2,4-diphenylcyclobutane-1,3-dicarboxylic acid (CBDA-1), which is also known as $\alpha$-truxillic acid.

Diacids similar to CBDA are widely used in modern materials (Fig. 1) ${ }^{5-8}$. A highly successful example is the aliphatic diacid, adipic acid, used to make Nylon $66^{9,10}$. Aromatic diacids have also found a variety of applications in materials. For instance, terephthalic acid, or benzene-1,4-dicarboxylic acid, is a chemical synthesized from a compound in crude oil ${ }^{11,12}$. It is a key building block in polyethylene terephthalate (PET), which is widely known for its use in plastic beverage bottles ${ }^{13,14}$. Researchers are currently trying to find a biomass-based diacid to serve as an alternative to terephthalic acid ${ }^{15,16}$. A prime candidate has been the furan-based building block 2,5-furandicarboxylic acid, which was named one of the top-12 value-added chemicals for "green" chemistry ${ }^{17,18}$. Compared to these classic diacids, which are either flexible aliphatic diacids and rigid aromatic diacids, CBDA represents a unique semi-flexible/semi-rigid building block in materials synthesis due to the presence of the small aliphatic ring with limited conformational freedom.

Despite the prevalence of the cyclobutane unit in many natural products ${ }^{19-25}$ and synthetic drugs ${ }^{26-35}$, it is rarely seen in materials with industrial applications ${ }^{36}$, most likely because concern about its stability has discouraged experimentation with this promising building block. When compared to five- and six-membered carbon rings, four-membered carbon rings are indeed less stable. The ring strain energy of cyclobutane is about 20.1 and $26.2 \mathrm{kcal} / \mathrm{mol}$ higher than that of cyclopentane and cylcohexane, respectively ${ }^{37}$. However, thermal $[2+2]$ cycloaddition is generally forbidden according to the Woodward-Hoffmann rules and it normally requires deep UV to cleave the four-membered carbon ring. Therefore, we hypothesized that cyclobutane has sufficient thermal

${ }^{1}$ Department of Chemistry, University of North Dakota, Grand Forks, ND, 58202, USA. ${ }^{2}$ Department of Chemistry and Biochemistry, North Dakota State University, Fargo, ND, 58102, USA. Correspondence and requests for materials should be addressed to Q.R.C. (email: chu@chem.und.edu) 
<smiles>[R]C1C(C(=O)O)C([R])C1C(=O)O</smiles>

trans-Cyclobutane-1,3-diacid (CBDA)<smiles>O=C(O)c1ccc(C(=O)O)cc1</smiles>

Terephthalic acid<smiles>O=C(O)CCCCC(=O)O</smiles>

Adipic acid<smiles>O=C(O)c1ccc(C(=O)O)o1</smiles>

\section{2,5-Furandicarboxylic acid}

Figure 1. Diacid building blocks for materials synthesis.

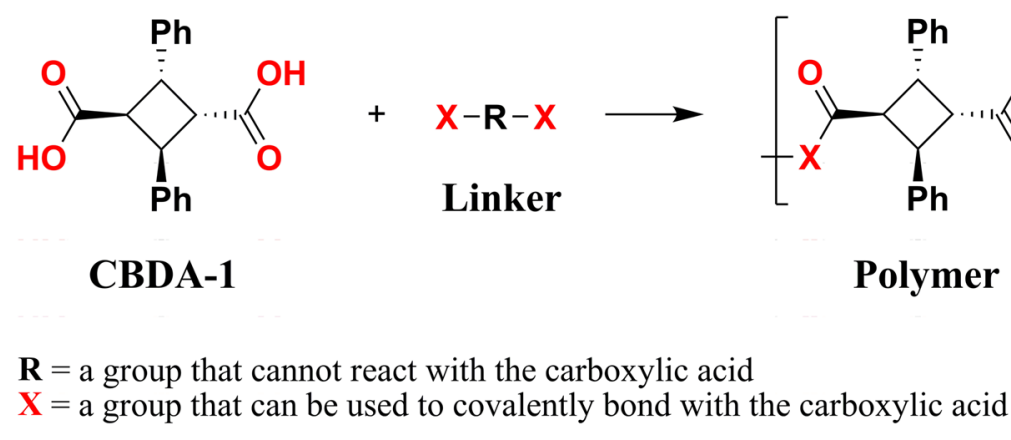

Figure 2. The strategy of using CBDA-1 as a building block in polymer synthesis.

and sunlight stability for many potential applications in materials. To test this hypothesis, we synthesized and examined the stability of CBDA-1 and several of its polymeric derivatives. Incorporating CBDA-1 into polymers requires a linker molecule capable of reacting with carboxylic acid (Fig. 2). A series of aliphatic diols were successfully used as linker molecules in combination with CBDA-1 to create polyesters that showed excellent stability.

\section{Results}

Synthesis of CBDA-1. The method used to synthesize trans-2,4-diphenyl-1,3-cyclobutanedicarboxylic acid (CBDA-1) has been known for several decades ${ }^{38}$. It can be readily synthesized from commercially available trans-cinnamic acid ${ }^{39-41}$ via photodimerization in the solid-state ${ }^{42-46}$. This process can be completed in 8 hours in near quantitative yield without side-products allowing the obtained CBDA-1 to be used in subsequent steps without further purification. The efficiency of the solvent-free photoreaction is presumably due to complementary $\pi-\pi$ interactions between adjacent trans-cinnamic acid molecules, which are potentiated by head-to-tail ( $\alpha$-form) packing in the solid state. On one end of the molecule, phenyl groups act as weak electron donating groups while carboxylic acid groups on the opposite end function as weak electron accepting groups. The end result is that the flat, conjugated trans-cinnamic acid molecules are relatively polar and prefer a head-to-tail packing formation because it is lower in energy ${ }^{42,47}$. Quality single crystals of trans-cinnamic acid were obtained in a mixed solvent of ethyl acetate and acetonitrile (1:1). X-ray diffraction analysis confirmed its head-to-tail packing. We found that the head-to-tail packing could be easily obtained in a variety of solvents including acetonitrile, acetone, toluene, methanol, THF, and chloroform showing that the $\alpha$-form is the dominant packing conformation for trans-cinnamic acid. Moreover, powder X-ray diffraction (PXRD) confirmed that the packing of commercial trans-cinnamic acid is the head-to-tail form because its powder pattern was nearly identical to that of the head-to-tail single crystal simulation (see Supplementary Figure S3). Consequently, the commercial trans-cinnamic acid powder can be used to produce the building block, CBDA-1, directly without recrystallization. It is also worthwhile to mention that only one of the five stereoisomers of the $[2+2]$ head-to-tail dimers was produced because solid state photoreaction normally proceeds with minimal movement of atoms (see Figure S2 in the Supplementary).

Thermal, chemical, and photochemical stability analyses. Despite the relatively straightforward synthetic pathway to create to CBDA-1, its utility as a building block in materials has been rarely studied. Our thermogravimetric analysis (TGA) and differential scanning calorimetry (DSC) study showed CBDA-1 was stable at $250^{\circ} \mathrm{C}$ and only lost $5 \%$ of its weight when the temperature is increased to $307^{\circ} \mathrm{C}$ (Fig. 3). The weight lost 

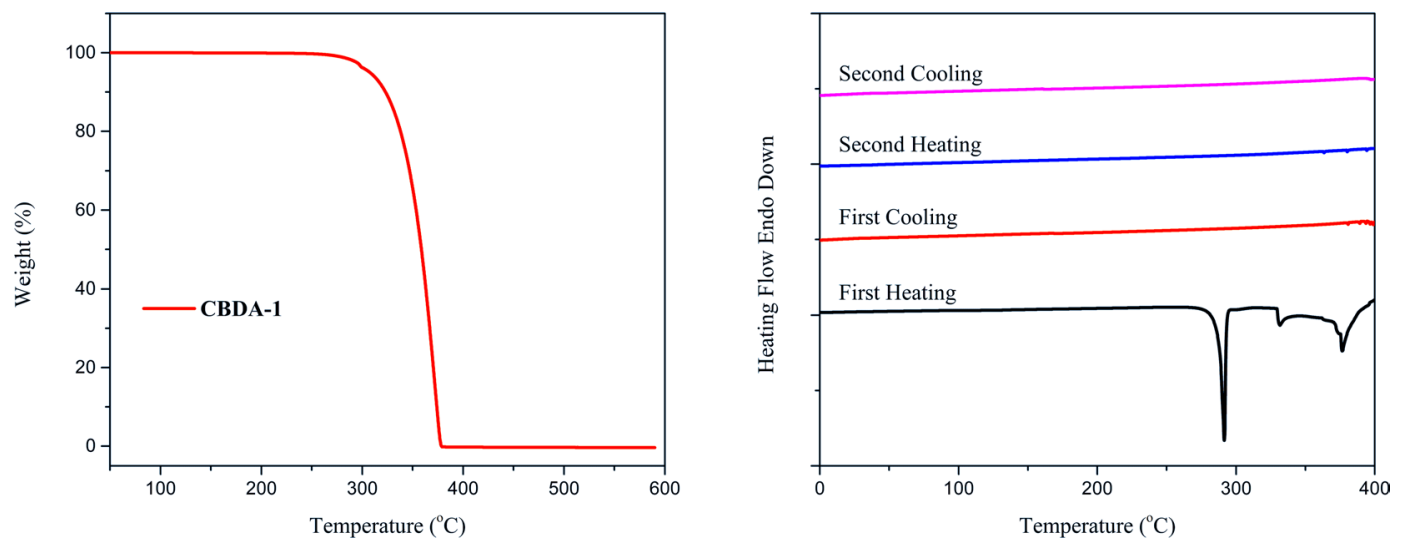

Figure 3. TGA (left) and DSC (right) of CBDA-1: TGA was recorded from $50^{\circ} \mathrm{C}$ to $600^{\circ} \mathrm{C}$ with a heating rate of $20^{\circ} \mathrm{C} \cdot \mathrm{min}^{-1}$ under $\mathrm{N}_{2}$ atmosphere. DSC was recorded from $0{ }^{\circ} \mathrm{C}$ to $400^{\circ} \mathrm{C}$ with a heating rate of $10^{\circ} \mathrm{C} \cdot \mathrm{min}^{-1}$ under $\mathrm{N}_{2}$ atmosphere.<smiles>O=C(O)[C@H]1[C@H](c2ccccc2)[C@H](C(=O)O)[C@@H]1c1ccccc1</smiles>
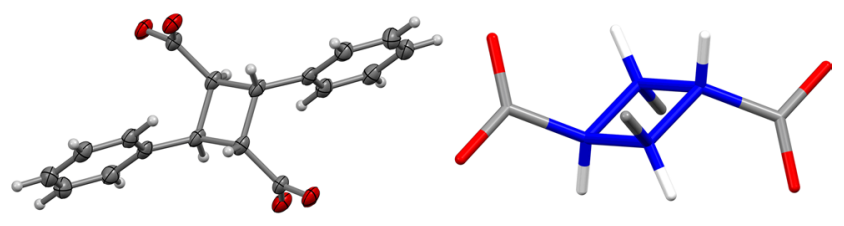

Figure 4. Structure of CBDA-1: (left) chemical structure of the building block; (middle) X-ray single crystal structure in Oak Ridge Thermal Ellipsoid Plot (ORTEP) representing at 50\% electron density of monomer structure; (right) single crystal structure in stick style with the cyclobutane ring highlighted in blue (two phenyl groups are omitted for clarity).

in TGA below $330^{\circ} \mathrm{C}$ may be due to evaporation because CBDA-1 melts around $276^{\circ} \mathrm{C}$ and it lost all weight at $378^{\circ} \mathrm{C}$ showing its decomposition at high temperature. The DSC curve suggested CBDA-1 started decomposing at $330^{\circ} \mathrm{C}$ in the first heating process. After decomposition, DSC showed no change in the first cooling and second heating processes. The TGA and DSC curves showed that CBDA-1 is thermally stable enough to be used as a building block in materials. The results are reasonable because [2+2] cycloaddition is generally photochemically allowed, but thermally forbidden. Meanwhile, its reverse thermal reaction, such as the pyrolysis of cyclobutane, is a stepwise process with a high energy barrier involving a radical intermediate.

After exposure of CBDA-1 under sunlight for a month or UV irradiation with a Hanovia medium pressure mercury lamp for two weeks, the sample showed no change in its FT-IR and ${ }^{1} \mathrm{H}$ NMR spectra. Comparison of the UV-Vis spectra of CBDA-1 and its starting material trans-cinnamic acid showed a clear blue shift with the maximum absorption moving from $270 \mathrm{~nm}$ to $208 \mathrm{~nm}$ after photoreaction (see Supplementary Figure S4). The formation of two $s p^{3}$ carbons between the phenyl ring and carboxylic acid group led to the deconjugation, which is responsible for the shift and sunlight stability of CBDA-1.

In addition to thermal and sunlight stability, the cyclobutane ring of CBDA-1 also shows good chemical stability. No changes were observed after boiling CBDA-1 in $6 \mathrm{M} \mathrm{HCl}$ at $100^{\circ} \mathrm{C}$ for 24 hours and its ${ }^{1} \mathrm{H} \mathrm{NMR} \mathrm{spectrum}$ confirmed that there was no isomerization or any other changes. As expected, CBDA-1 reacted with $\mathrm{KOH}$ via acid-base neutralization reaction. After boiling CBDA-1 in $15 \mathrm{M} \mathrm{KOH}$ aqueous solution for 24 hours, the mixture was acidized with $\mathrm{HCl}$ to $\mathrm{pH}=3$ and $\mathbf{C B D A}-\mathbf{1}$ was precipitated out and filtered. Its $^{1} \mathrm{H}$ NMR showed no change.

Single crystal X-ray diffraction analysis. The single crystal structure of CBDA-1 obtained in our lab was consistent with the literature report ${ }^{38}$. Cyclobutane rings in the structure adopted two different orientations appearing in an alternating fashion within linear hydrogen bond chains, which were randomly dispersed throughout the crystal matrix, resulting in a disordered structure (see Supplementary Figure S1). This may have occurred because the relatively small cyclobutane ring did not fully fill the empty space generated in the crystal matrix by the hydrogen bond chain and the relatively rigid structure of CBDA-1. A straightforward single crystal structure was obtained by preparing a CBDA-1 salt, $\alpha$-truxillate-dibutylaminium, in the solvent solution ethanol/ water/dimethylformamide (1:1:1). The short-chain flexible cation, butylaminium, does not destroy the structure of CBDA-1, but can be used to fill spaces in the crystal lattice reducing the chance of disorder. As expected, the single crystal of the CBDA-1 salt shows that the four carbon atoms on the cyclobutane ring are coplanar and have carbon-carbon bond distances of around $1.57 \AA$ (Fig. 4). The two carboxylic groups on opposite sides of the cyclobutane ring have a $180^{\circ}$ angle between them and are offset by $1.40 \AA$, which is a unique characteristic compared to other well-known diacids. The distance between the two carboxylic groups is $4.76 \AA$. This distance is 


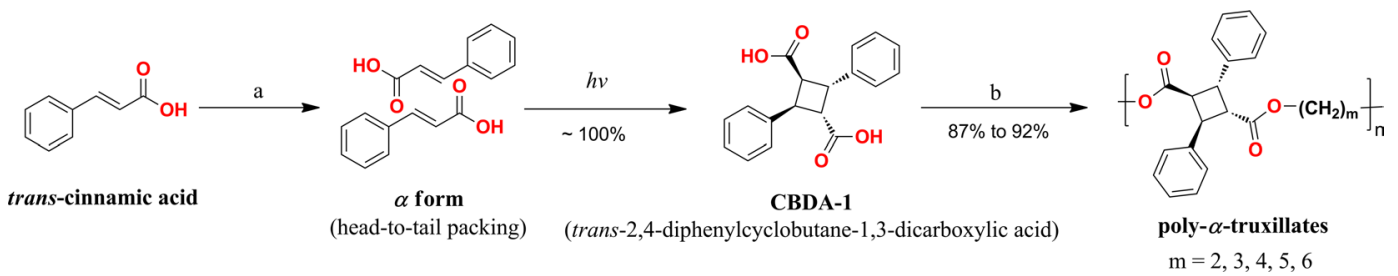

Figure 5. The synthesis of CBDA-1 and poly- $\alpha$-truxillate. (a) The commercially available trans-cinnamic acid is in $\alpha$-form (head-to-tail packing). Further crystallization is not necessary. (b) Diol, DCC, DMAP, $\mathrm{CH}_{3} \mathrm{CN}_{\text {, r.t. }}$ $18 \mathrm{~h}$.

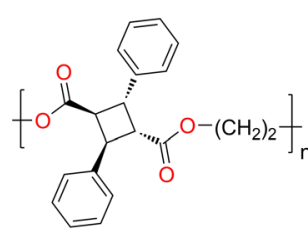

Repeating Unit of PEAT Chemical Formula: $\mathrm{C}_{20} \mathrm{H}_{18} \mathrm{O}_{4}$ Exact Mass: 322.12

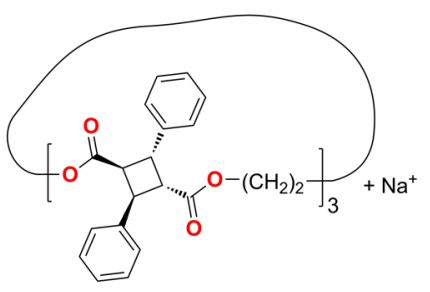

Chemical Formula: $\left[\mathrm{C}_{60} \mathrm{H}_{54} \mathrm{NaO}_{12}\right]^{+}$ Monoisotopic mass: 989.3513 Found: 989.3472<smiles>CC(C)(C)OC(=O)C1[C@H](c2ccccc2)C(C(=O)OCCCCCCO)[C@H]1c1ccccc1</smiles>

Chemical Formula: $\left[\mathrm{C}_{62} \mathrm{H}_{60} \mathrm{NaO}_{14}\right]^{+}$ Monoisotopic mass: 1051.3880 Found: 1051.3832

Figure 6. The repeating unit of PEAT (left), cycled PEAT (middle), and linear PEAT (right).

similar to the distance between two carboxylic groups on furan-based building block 2,5-furandicarboxylic acid as shown in Fig. 1. The spatial orientation and distance of the two carboxylic acid groups makes it suitable for polymer construction. The cyclobutane ring has two exchangeable conformations, planar and puckered, with about 23 degrees difference between them ${ }^{48}$. The limited conformational freedom of the cyclobutane ring is expected to give CBDA-1 a unique semi-rigid character ${ }^{27,49,50}$.

Synthesis of poly- $\boldsymbol{\alpha}$-truxillate. To investigate the possibility of using CBDA-1 as a building block in materials, it was polymerized with a series of linear diols through a condensation reaction (Fig. 5). Five poly- $\alpha$-truxillates were produced, poly(ethylene- $\alpha$-truxillate) (PEAT), poly(propylene- $\alpha$-truxillate) (PPAT3), poly(1,4-butylene- $\alpha$-truxillate) (PBAT), poly(1,5-pentylene- $\alpha$-truxillate) (PPAT), poly(1,6-hexylene- $\alpha$-truxillate) (PHAT). Out of the five polymers synthesized, only PPAT3 was a liquid at room temperature, so it is not included in the following discussion. Powder X-ray diffraction patterns of these four poly- $\alpha$-truxillates showed that they are semi-crystalline (see Supplementary Figure S12). Two series of peaks were observed in the HRMS spectrum of PEAT (Fig. 6), which was determined by preliminary MALDI-TOF analysis. They have a repeating unit with $m / z=322.12$ that corresponds with the unit mass of PEAT $\left(\mathrm{C}_{20} \mathrm{H}_{18} \mathrm{O}_{4} m / z=322.12\right)$. One repeating peak of PEAT is ' $m / z=322.12 \times \mathrm{n}+22.99\left(\mathrm{Na}^{+}\right)$' which may indicate that some cycled polyesters exist in the product. For example, ' $\mathrm{m} / z=322.12 \times 3+22.99=989.35$ '. Another repeating peak of PEAT is ' $\mathrm{m} / \mathrm{z}=322.12 \times \mathrm{n}+62.04$ (end-group) $+22.99\left(\mathrm{Na}^{+}\right)^{\prime}$. This result suggests there are linear polyesters with end-groups $\mathrm{HO}-\left(\mathrm{CH}_{2}\right)_{2}-$ and $-\mathrm{OH}$. For example, ' $\mathrm{m} / \mathrm{z}=322.12 \times 3+62.04+22.99=1051.39$ '. The MS analysis of PEAT revealed both linear and cycled fragments might be present in PEAT. This phenomenon of two different repeating peaks in HRMS spectra was also observed in PBAT, PPAT, and PHAT. Both NMR and HRMS spectra indicated that PEAT was the only compound with a significant number of cycled products. This is probably because it is difficult to form cycled products when the linker molecules contain long and flexible carbon chains. The maximum molecular weights observed in HRMS spectra indicate hexamers. The GPC curves of the poly- $\alpha$-truxillates in THF solution showed a narrow molecular weight distribution with the polydispersity indices (PDI) within the 1.47-1.88 range (see Supplementary Table S2).

Thermal, chemical, and photochemical property analyses. Thermogravimetric analysis (TGA, Fig. 7) results indicated the poly- $\alpha$-truxillates started to decompose around $350^{\circ} \mathrm{C}$, which are comparable to the thermostabilities of terephthalic acid or 2,5-furandicarboxylic acid based polyesters ${ }^{51}$. DSC was used to analyze the glass transition temperature $\left(T_{\mathrm{g}}\right)$ of the four polyesters. Supplementary Figure $\mathrm{S} 17$ shows a decreasing trend of the poly- $\alpha$-truxillates' $T_{\mathrm{g}} \mathrm{s}$ with increasing diol carbon chain length. The $T_{\mathrm{g}}$ of PEAT is $81^{\circ} \mathrm{C}$ whereas the $T_{\mathrm{g}}$ of PPAT is $64^{\circ} \mathrm{C}$. This trend in the $T_{\mathrm{g}} \mathrm{s}$ may be attributed to the increased flexibility of longer carbon chains, which make it easier for the polyester to rotate or twist. After the first heating and cooling process, the DSC curve showed an obvious decreasing trend of $T_{\mathrm{g}} \mathrm{s}$ in the second heating process. This phenomenon may be due to the annealing effect of the first heating process. After heating polyesters to $250^{\circ} \mathrm{C}$, the polyesters will be scattered and mixed equally, which may lead to the decreasing $T_{\mathrm{g}} \mathrm{s}$. The poly- $\alpha$-truxillates showed excellent chemical stability. When treated with common solvents such as diethyl ether, hexane, chloroform, acetonitrile, acetone, DCM, THF, $\mathrm{EtOH}, \mathrm{EtOAc}$, and DMSO, the poly- $\alpha$-truxillates showed no degradation. Hydrolysis was not observed after 24 hours refluxing the poly- $\alpha$-truxillates in $5 \mathrm{M}$ aqueous $\mathrm{NaOH}$ or $6 \mathrm{M} \mathrm{HCl}$. Photochemical stability tests were 


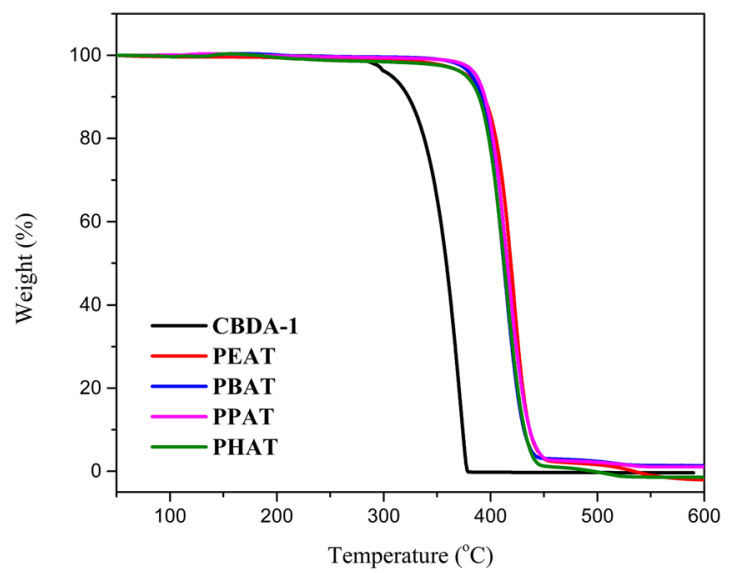

Figure 7. TGA of poly- $\alpha$-truxillates: recorded from $50^{\circ} \mathrm{C}$ to $600^{\circ} \mathrm{C}$ with a heating rate of $20^{\circ} \mathrm{C} \mathrm{min}$ minder $^{-1}$ und atmosphere.

carried out under ultraviolet irradiation using a Hanovia medium pressure mercury lamp and were monitored by FT-IR and NMR. The preliminary results showed slight degradation of the poly- $\alpha$-truxillates after continuous ultraviolet irradiation for one week, which was similar to PET ${ }^{52}$.

\section{Discussion}

Both starting materials of the polymers, the diols and cinnamic acid, can be obtained from biomass ${ }^{43}$. While diols have been widely used in making plastics, cinnamic acid has found its applications in flavors, perfumes, synthetic indigo, and certain pharmaceuticals ${ }^{39}$. It has recently been adequately derived from a side product of biofuel manufacture and from other renewable sources including glucose via engineered E. coli ${ }^{53-55}$. Biomass-derived cinnamic acid has also been reported to be used for styrene synthesis through a decarboxylation reaction to produce environmentally friendly polystyrene ${ }^{56}$. Meanwhile, the photoreaction to synthesize CBDA-1 was able to be carried out under sunlight. Thus, CBDA-1 could be produced as a greener diacid to replace or partially replace commodity petrochemicals such as terephthalic acid in the future.

\section{Conclusion}

A promising building block CBDA-1 was introduced to materials synthesis in this study. The simple preparation of CBDA-1 has been demonstrated and discussed. Our study has shown that using CBDA-1 in the construction of materials is beneficial not only because it can be produced from bio-based starting materials, but also because it has thermal, sunlight, and chemical stability. Moreover, the four-membered carbon ring structure of CBDA-1 offers a unique semi-rigid property for materials. These features of CBDA-1 allow it to be used directly in making new polymers or be added into known polymer recipes in certain ratio to modify their physical properties such as transparency and glass transition temperature $\left(T_{\mathrm{g}}\right)^{39,57}$. The successful synthesis of a new family of polyesters presented in this work confirmed that CBDA-1 is a useful building block for polymers. Initial thermal, chemical, and photochemical analyses revealed stabilities of the newly synthesized cyclobutane-containing polyesters which are comparable to those of PET. As novel building blocks, CBDA-1 and its congeners will provide great opportunities in producing a variety of materials (e.g., polyesters, polyamides, polycyclobutanes, copolymers, and coordination polymers) with new properties and applications ${ }^{58-60}$.

\section{Methods}

Solid state photodimerization. Commercially available trans-cinnamic acid (2 g) was scattered on a $10^{\prime \prime} \times 10^{\prime \prime}$ glass plate. The plate was put outside in sunlight or in a photoreactor with UV lamp. The process of photodimerization was monitored by FT-IR which showed completion after $10 \mathrm{~h}$ under sunlight and $8 \mathrm{~h}$ under a mercury lamp, respectively. About $1.96 \mathrm{~g}$ of CBDA-1 (trans-2,4-diphenyl-1,3-cyclobutanedicarboxylic acid or $\alpha$-truxillic acid) was obtained.

Single crystal growth and characterization. trans-Cinnamic acid: To achieve high quality single crystals for X-ray data collection, $60 \mathrm{mg}$ of trans-cinnamic acid was added to a mixture of ethyl acetate and acetonitrile $(1: 1,20 \mathrm{~mL})$. The mixture was allowed to stand in the fume hood until single crystals were formed. CBDA-1: $10 \mathrm{mg}$ of $\alpha$-truxillic acid was dissolved in $20 \mathrm{~mL}$ of ethanol. The mixture was sonicated for $30 \mathrm{~min}$. The obtained clear solution was allowed to stand at room temperature without cover for three days or until the crystals were formed. CBDA-1 salt ( $\alpha$-truxillate-dibutylaminium): $20 \mathrm{mg}$ of $\alpha$-truxillic acid was dissolved in DMF (5 mL) in a $20 \mathrm{~mL}$ vial. A mixture of ethanol $(5 \mathrm{~mL})$, water $(5 \mathrm{~mL})$ and $n$-butylamine $(0.5 \mathrm{~mL})$ was then added to this solution. The mixture was heated to $70^{\circ} \mathrm{C}$ and stirred for $10 \mathrm{mins}$. Crystals were obtained in around three days.

General procedure for poly- $\alpha$-truxillate synthesis. CBDA-1. Ethylene glycol, $N, N^{\prime}$-dicyclohexylcarbodiimide (DCC) and 4-dimethylaminopyridine (DMAP) were added to a solvent of acetonitrile $\left(\mathrm{CH}_{3} \mathrm{CN}\right.$, 
$20 \mathrm{~mL}$ ). The mixture was stirred at room temperature for $20 \mathrm{~h}$ and mixed with $20 \mathrm{~mL}$ of chloroform. The mixture was filtered via column chromatography to give product poly(ethylene- $\alpha$-truxillate) (PEAT) as a white solid.

Data availability. The data supporting the findings of this study are available within the article and its Supplementary Information files. All data are available from the corresponding author upon reasonable request.

The crystallographic data for trans-cinnamic acid, CBDA-1, and CBDA-1 dibutylaminium salt are available

in Cambridge Crystallographic Data Centre (CCDC\# 986274, 1547787, and 1547788).

\section{References}

1. Allcock, H., Lampe, F. \& Mark, J. Contemporary Polymer Chemistry. Pearson (2003).

2. Peacock, A. \& Calhoun, A. Polymer Chemistry: Properties and Applications (2006).

3. Schoedel, A., Li, M., Li, D., O’keeffe, M. \& Yaghi, O. M. Structures of Metal-Organic Frameworks with Rod Secondary Building Units. Chem Rev, (2016).

4. Williams, I. D. Metal-organic frameworks: 3D frameworks from 3D printers. Nat Chem 6, 953-954 (2014).

5. Edlund, U. \& Albertsson, A. C. Polyesters based on diacid monomers. Adv Drug Deliv Rev 55, 585-609 (2003).

6. Ouimet, M. A., Faig, J. J., Yu, W. \& Uhrich, K. E. Ferulic Acid-Based Polymers with Glycol Functionality as a Versatile Platform for Topical Applications. Biomacromolecules 16, 2911-2919 (2015).

7. Vilela, C. et al. The quest for sustainable polyesters - insights into the future. Polym Chem 5, 3119-3141 (2014).

8. Zhang, Y.-R. et al. Poly(oleic diacid-co-glycerol): Comparison of Polymer Structure Resulting from Chemical and LipaseCatalysis. In: Biobased Monomers, Polymers, and Materials. American Chemical Society (2012).

9. Cornils, B. \& Lappe, P. Dicarboxylic Acids, Aliphatic. In: Ullmann's Encyclopedia of Industrial Chemistry. Wiley-VCH Verlag GmbH \& Co. KGaA (2000)

10. Palmer, R. J. Polyamides, Plastics. In: Encyclopedia of Polymer Science and Technology. John Wiley \& Sons, Inc (2002).

11. Ichikawa, Y., Yamashita, G., Tokashiki, M. \& Yamaji, T. New Oxidation Process for Production of Terephthalic Acid from $p$-Xylene. Ind Eng Chem 62, 38-42 (1970).

12. Ogata, Y., Tsuchida, M. \& Muramoto, A. The Preparation of Terephthalic Acid from Phthalic or Benzoic Acid. J Am Chem Soc 79, 6005-6008 (1957).

13. Fakirov, S. Handbook of thermoplastic polyesters. Wiley-VCH (2002).

14. East, A. J. Polyesters, Thermoplastic. In: Encyclopedia of Polymer Science and Technology. John Wiley \& Sons, Inc (2002).

15. De Jong, E., Dam, M. A., Sipos, L. \& Gruter, G. J. M. Furandicarboxylic Acid (FDCA), A Versatile Building Block for a Very Interesting Class of Polyesters. In: Biobased Monomers, Polymers, and Materials. American Chemical Society (2012).

16. Beckman, E. J. Sustainable chemistry: Putting carbon dioxide to work. Nature 531, 180-181 (2016).

17. Bozell, J. J. \& Petersen, G. R. Technology development for the production of biobased products from biorefinery carbohydrates-the US Department of Energy's “Top 10” revisited. Green Chem 12, 539-554 (2010).

18. Werpy, T. \& Petersen, G. Top Value Added Chemicals from Biomass: Volume 1 - Results of Screening for Potential Candidates from Sugars and Synthesis Gas. National Renewable Energy Laboratory (2004).

19. Rosa, M. O., Albertina, G. M. \& Graciela, Y. M. Cyclobutane Biomolecules: Synthetic Approaches to Amino Acids, Peptides and Nucleosides. Curr Org Chem 9, 237-259 (2005).

20. Hong, Y. J. \& Tantillo, D. J. How cyclobutanes are assembled in nature - insights from quantum chemistry. Chem Soc Rev 43, 5042-5050 (2014).

21. Fan, Y.-Y., Gao, X.-H. \& Yue, J.-M. Attractive natural products with strained cyclopropane and/or cyclobutane ring systems. Sci China Chem 59, 1126-1141 (2016).

22. Goodman, C. Synthesis: Cyclobutanes prove charlatans. Nat Chem Biol 8, 678-678 (2012).

23. Dembitsky, V. M. Naturally occurring bioactive Cyclobutane-containing (CBC) alkaloids in fungi, fungal endophytes, and plants. Phytomedicine 21, 1559-1581 (2014).

24. Dembitsky, V. M. Bioactive cyclobutane-containing alkaloids. J Nat Med 62, 1-33 (2008).

25. Bucholtz, K. M., Gareiss, P. C., Tajc, S. G. \& Miller, B. L. Synthesis and evaluation of the first cis-cyclobutane-containing receptor for lipid A. Org Biomol Chem 4, 3973-3979 (2006).

26. Fu, N.-Y., Chan, S.-H., Wong, H. N. C. The Application of Cyclobutane Derivatives in Organic Synthesis. In: The Chemistry of Cyclobutanes. John Wiley \& Sons, Ltd (2006)

27. Rappoport, Z. \& Liebman, J. F. The Chemistry of Cyclobutanes, 2 Volume Set. Wiley (2005)

28. Namyslo, J. C. \& Kaufmann, D. E. The Application of Cyclobutane Derivatives in Organic Synthesis. Chem Rev 103, 1485-1538 (2003).

29. White, J. D., Li, Y., Kim, J. \& Terinek, M. Cyclobutane Synthesis and Fragmentation. A Cascade Route to the Lycopodium Alkaloid (-)-Huperzine A. J Org Chem 80, 11806-11817 (2015).

30. Maimone, T. J. \& Baran, P. S. Modern synthetic efforts toward biologically active terpenes. Nat Chem Biol 3, 396-407 (2007).

31. Howard, C. C. et al. Total synthesis of prostaglandin-F2[small alpha] involving stereocontrolled and photo-induced reactions of bicyclo[3.2.0]heptanones. J Chem Soc, Perkin Trans 1, 852-857 (1980).

32. Boyer, F.-D. \& Ducrot, P.-H. Syntheses of Cyclobutane Derivatives: Total Synthesis of $(+)$ and $(-)$ Enantiomers of the Oleander Scale Aspidiotus nerii Sex Pheromone. Eur J Org Chem 1999, 1201-1211 (1999).

33. Crimmins, M. T. \& Mascarella, S. W. Intramolecular photocycloaddition-cyclobutane fragmentation: total synthesis of (+-)-silphinene. J Am Chem Soc 108, 3435-3438 (1986).

34. Crimmins, M. T. \& Deloach, J. A. Intramolecular photocycloadditions-cyclobutane fragmentation: total synthesis of (+-)-pentalenene, (+-)-pentalenic acid, and (+-)-deoxypentalenic acid. J Am Chem Soc 108, 800-806 (1986).

35. Gutekunst, W. R. \& Baran, P. S. Total Synthesis and Structural Revision of the Piperarborenines via Sequential Cyclobutane C-H Arylation. J Am Chem Soc 133, 19076-19079 (2011).

36. Making a lasting impression: Tritan ${ }^{\text {TM }}$ copolyester http://www.eastman.com/Brands/Eastman_Tritan/ (Accessed in September 2017).

37. Anslyn, E. V. \& Dougherty, D. A. Chapter 2: Strain and Stability. Modern Physical Organic Chemistry. University Science (2006).

38. Abdelmoty, I. et al. Polymorphism of Cinnamic and $\alpha$-Truxillic Acids: New Additions to an Old Story. Cryst Growth Des 5, 2210-2217 (2005).

39. Garbe, D. C A. In: Cinnamic Acid, Ulmann's Encyclopedia of Industrial Chemistry. Wiley-VCH Verlag GmbH \& Co. KGaA (2000).

40. De, P., Baltas, M. \& Bedos-Belval, F. Cinnamic Acid Derivatives as Anticancer Agents - A Review. Curr Med Chem 18, 1672-1703 (2011).

41. Liu, L., Hudgins, W. R., Shack, S., Yin, M. Q. \& Samid, D. Cinnamic acid: A natural product with potential use in cancer intervention. Int J Cancer 62, 345-350 (1995).

42. Wang, Z. et al. Polyladderane Constructed from Gemini Monomer via Photoreaction. Angew Chem Int Ed 56, 12155-12159 (2017).

43. Randazzo, K., Wang, Z., Wang, Z. D., Butz, J. \& Chu, Q. R. Lighting the Way to Greener Chemistry: Incandescent Floodlights as a Facile UV Light Source for Classic and Cutting-Edge Photoreactions. ACS Sustain Chem Eng 4, 5053-5059 (2016). 
44. Wang, Z. et al. Linear polyester synthesized from furfural-based monomer by photoreaction in sunlight. Green Chem 17, 4720-4724 (2015).

45. Wang, Z. et al. Stereoregular Two-Dimensional Polymers Constructed by Topochemical Polymerization. Macromolecules 48, 2894-2900 (2015).

46. Chu, Q., Swenson, D. C. \& Macgillivray, L. R. A single-crystal-to-single-crystal transformation mediated by argentophilic forces converts a finite metal complex into an infinite coordination network. Angew Chem Int Ed 44, 3569-3572 (2005).

47. Zhu, S., Qin, C., Xu, G. \& Chu, Q. A convenient synthesis of a new push-pull alkenes: $\beta$-alkoxyl vinyl trifluoromethyl sulfones. Tetrahedron Lett 39, 5265-5268 (1998).

48. Cotton, F. A. \& Frenz, B. A. Conformations of cyclobutane. Tetrahedron 30, 1587-1594 (1974).

49. Francis, A. \& Carey, R. J. S. Advanced Organic Chemistry Part A: Structure and Mechanisms. Springer US (2007).

50. Brown, W. H., Iverson, B. L., Anslyn, E. \& Foote, C. S. Organic Chemistry 7 edition. Cengage Learning (2013).

51. Thiyagarajan, S. et al. Biobased furandicarboxylic acids (FDCAs): effects of isomeric substitution on polyester synthesis and properties. Green Chem 16, 1957-1966 (2014).

52. Day, M. \& Wiles, D. M. Photochemical degradation of poly(ethylene terephthalate). I. Irradiation experiments with the xenon and carbon arc. J Appl Polym Sci 16, 175-189 (1972).

53. Scott, E., Peter, F. \& Sanders, J. Biomass in the manufacture of industrial products - the use of proteins and amino acids. Appl Microbiol Biotechnol 75, 751-762 (2007).

54. Mckenna, R. \& Nielsen, D. R. Styrene biosynthesis from glucose by engineered E. coli. Metab Eng 13, 544-554 (2011).

55. Goodman, C. Metabolic engineering: A plastic pathway. Nat Chem Biol 7, 576-576 (2011).

56. Spekreijse, J., Le Notre, J., Van Haveren, J., Scott, E. L. \& Sanders, J. P. M. Simultaneous production of biobased styrene and acrylates using ethenolysis. Green Chem 14, 2747-2751 (2012).

57. Köpnick, H., Schmidt, M., Brügging, W., Rüter, J. \& Kaminsky, W. Polyesters. In: Ullmann's Encyclopedia of Industrial Chemistry. Wiley-VCH Verlag GmbH \& Co. KGaA (2000).

58. Berger, W. T. et al. Targeting Fatty Acid Binding Protein (FABP) Anandamide Transporters - A Novel Strategy for Development of Anti-Inflammatory and Anti-Nociceptive Drugs. PLoS ONE 7, e50968 (2012).

59. Arafat, M. T., Tronci, G., Yin, J., Wood, D. J. \& Russell, S. J. Biomimetic wet-stable fibres via wet spinning and diacid-based crosslinking of collagen triple helices. Polymer 77, 102-112 (2015).

60. Batten, S. R. Coordination Polymers: Design, Analysis and Application. RSC Publishing (2008).

\section{Acknowledgements}

This material is based upon work supported by the National Science Foundation Grant (NSF EPSCoR Award IIA-1355466).

\section{Author Contributions}

Q.R.C. and Z.W. conceived the research and designed the experiments. Z.W. performed most of the experiments. M.M. carried out the photochemical stability tests. R.S. obtained the polydispersity indices. A.U. and Q.R.C. collected and refined the crystal structures. The manuscript was prepared by Q.R.C., Z.W., and B.M. with inputs from M.M., R.S., and Z.D.W. All authors discussed the results and commented on the manuscript.

\section{Additional Information}

Supplementary information accompanies this paper at https://doi.org/10.1038/s41598-017-13983-z.

Competing Interests: The authors declare that they have no competing interests.

Publisher's note: Springer Nature remains neutral with regard to jurisdictional claims in published maps and institutional affiliations.

Open Access This article is licensed under a Creative Commons Attribution 4.0 International License, which permits use, sharing, adaptation, distribution and reproduction in any medium or format, as long as you give appropriate credit to the original author(s) and the source, provide a link to the Creative Commons license, and indicate if changes were made. The images or other third party material in this article are included in the article's Creative Commons license, unless indicated otherwise in a credit line to the material. If material is not included in the article's Creative Commons license and your intended use is not permitted by statutory regulation or exceeds the permitted use, you will need to obtain permission directly from the copyright holder. To view a copy of this license, visit http://creativecommons.org/licenses/by/4.0/.

(C) The Author(s) 2017 